\title{
Moral Judgments of Foreign Cultures and Bygone Epochs. A Two-Tier Approach
}

\author{
ARNOLD ECKHART, DÜSSELDORF
}

\section{Exposition of the Problem}

The problem that I would like to address in this paper is how we can form sound moral judgments of actions that take place outside of our own historical and cultural context. Strictly speaking, there are two different problems, one concerning judgments of historical events and one concerning judgments of contemporary cultures. However, there is a strong logical similarity between both types of moral judgments insofar as they both concern judgments about something that takes place in a life context different from our own.

It is, I believe, easy to see that this is indeed a problem in the sense that the historical or cultural context does make a difference concerning our moral judgments. For example, when Alexander the Great conquered the city of Tyros he crucified all surviving men in the city and sold the women and children into slavery (Fox). Yet, despite the severe violation of human rights during his conquests historians usually do not tend to place Alexander in the same league with dictators like Saddam Hussein or Kim Jong-il. Or, to take another example, it is reported that some tribes in the highlands of New Guinea honor newly deceased relatives by devouring their corpses (Diamond). Abhorrent as it may seem to us, there would be no point in blaming the tribesmen of New Guinea for keeping up a revered archaic custom.

Thus, there are many cases where a certain amount of cultural or historical moral relativism seems appropriate. It is simply a fact that values change over time and differ between diverse cultures of the same epoch. If we do not take account of this fact in our ethical convictions, we risk to become hopelessly parochial or to slip into absurdities. On the other hand, the opposite standpoint, a complete cultural and historical relativism, would be equally unsound. For, to take an extreme example, there is certainly no way of justifying the atrocities that communist or fascist regimes committed during the last century on the grounds that tolerating licentious manslaughter was common at that time. 
Obviously, we can neither leave historical and cultural contexts aside when forming moral judgments nor must we fully submit to these contexts. The right solution has to keep the golden mean somewhere between these extremes.

\section{Breaking up the Question: Judgments of Institutions and Judgments of People}

Moral judgments can be formed with different goals in mind. They can be formed for the purpose of solving conflicts, which is the case when a judge decides the verdict. Or they can be formed merely with the aim of gaining a well reasoned moral opinion on some subject matter. This is the goal of historians when they evaluate historical persons and their actions. The former requires that we reach definite and unambiguous solutions, while the latter allows some amount of ambiguity. If it is just for the sake of forming an opinion, we may look at the issue from different angles without reducing the different perspectives to a single ultimate decision. The following discussion is primarily concerned with well-reasoned moral opinions. How the cases where definite decisions must be made are to be dealt with will only briefly be considered later, in the concluding paragraphs of this paper.

What are the reference points that we should look out for in order to form well-reasoned moral judgments of strange cultures and bygone epochs, if we are to avoid the extremes of imposing our set of values (moral absolutism) and moral relativism alike? My proposal of a solution is to make a fundamental difference between the judging of social institutions, including moral codes, and the judging of people acting within the social institutions of their time and culture. While the former may be evaluated rigorously, only taking into account the objective possibilities for having other institutions at a certain development stage, the latter should be judged in the context of the moral common sense of the respective time and culture.

\subsection{Judgments of Institutions and Moral Systems}

When looking at moral systems or social institutions abstractly, we do not need to take into account in how far it can be expected from a human being to emancipate herself or himself from traditional moral prejudices and to rise above the level of the current social surrounding. Under this perspective, we therefore do not need to have any hesitation to judge rigorously 
according to our own ethical standards. The reason why we should do so is simply that morals matter. Moral rules regulate how people should treat each other, and it is a matter of great importance how people are treated anywhere in this world. More emphatically, we could say that there exists such a thing as a world responsibility, which compels us and at the same time entitles us to take up a stance on what happens to human beings anytime and anywhere in this world. ${ }^{1}$ On a mythical level, our world responsibility is the expression of the unity of mankind that is, of the moral bonds that connect any human in this world with any other human being. If we assume world responsibility in this sense, we cannot suspend our moral judgment merely on behalf of the remoteness of context - at least not when important matters are at stake.

There should be only two restrictions to the rigor of moral judgment in this case: limits of possibilities and limits of importance. "Limits of possibility" describe the fact that certain morally approvable goals may not be feasible in some contexts. Take, for example, the introduction of liberal democracy. This form of government (most probably) cannot exist if not certain prerequisites concerning social structure, economic prosperity, educational level and the like are met (Schmidt). Moreover, in order to install a liberal democracy, a good deal of technical knowledge about institutional arrangements and procedures is required, a technical knowledge that is in its fully developed form a relatively recent invention. Therefore, it would be absurd to make a moral point of the absence of liberal democracy in, say, medieval Europe. The same holds true for the intercultural case, although it is a little less obvious there. For, if the technical knowledge required to realize some moral goal exists somewhere in this world then it should in principle be available anywhere. However, there can still be objective limits of possibilities that preclude the realization of this or other moral goods in a certain context. In this case, we cannot simply judge according to our own moral standards, which tacitly rely on the existence of certain "objective possibilities" (Weber).

Regarding the limits of possibilities as a restriction of moral judgment, there is a danger of mistakenly or dishonestly assuming limits of possibility where there really are none. The problem of determining objective possibilities or the limits thereof is, however, an epistemological problem more than one of moral philosophy. It is precisely the problem that historians and social scientists face when they want to assess the "objective possibility"

\footnotetext{
${ }^{1}$ The idea of world responsibility is borrowed from the total responsibility of the individual for everything that some strata of the philosophy of existentialism assume.
} 
(Weber) of historical developments. As our knowledge of the laws that govern social developments or the course of history is extremely limited, determining the "objective possibilities or impossibilities" of social development is quite a difficult task. The techniques by which social scientists help themselves out when they want to assess the "objective possibilities" that a given historical situation offers include the comparison with similar situations at a different place or time, or looking at the alternatives that were (or are) under discussion among the actors within these situations, presuming that something that was seriously considered by the contemporaries was probably not totally unrealistic. Roughly speaking, everything that ever existed represents a possibility, but it may still not be a viable alternative in a given situation, and conversely, some possibilities may never have been noticed or even thought of and would still be realistic alternatives.

In the intercultural context, the question is frequently raised whether the adoption of certain values, for example modern values like human rights or religious tolerance or democratic government, is compatible with a certain cultural background, say Islamic culture. This is an important question concerning "objective possibilities", because if there really would be such an incompatibility of modern values and cultural tradition then demanding the adoption of modern values would entail nothing less than the abandonment of a culture. To answer the question, whether the adoption of modern values is compatible with retaining the traditional culture, a comparison with our own culture might help. There was indeed a time when Christian occidental culture posed quite a contrast to the above-mentioned "modern values". However, the propagation of these values through the movement of Enlightenment and ultimately their adoption did not lead to the abandonment of Christian occidental culture but only to a transformation of this culture. There is no reason why a similar transformation should be inaccessible to other cultures, although we will potentially have to face the fact that the members of other cultures may perhaps not want to adopt modern values. But since there is an objective possibility of reconciling Islamic culture with modern values, we do not need to have any hesitations about criticizing the insufficient observance of, say, the human rights in many Islamic countries today.

The other restriction for the judgment of moral systems and institutions of foreign cultures or past epochs concerns limits of importance of the subject matter at hand. The "importance of the subject matter" depends on the rank of the moral values concerned and on the level of being involved, 
which in turn depends on spatial and temporal distance and the strength or weakness of social or just empathetic ties. We can call the principle according to which the importance of a moral subject matter decreases with remoteness the principle of locality. A good example for the employment of this principle are burial rites. In most countries (including western countries) these are strictly regulated by the law and strong feelings are involved with regard to the appropriateness of the respective ceremonial proceedings. Yet, although the burial rites in different countries may strongly contradict each other, this is hardly a matter of intercultural controversy. As their regulation by law testifies, this does by no means entail that they are morally neutral.

There exists, however, a difference here between the intercultural case and the historical case. In the historical case, the moral importance may indeed decrease until almost nothing is left. Historians do not really need to argue about the human rights violations that occurred during Alexander's conquests, if only because there are other aspects of these happenings that are of much greater historical interest. But in contemporary times, if in some place of the world severe violations of human rights occur then the moral aspect cannot be ignored.

Thus we could say that the importance of a moral question is the smaller the farther away it occurs and the lower the rank of the values involved, but that - if basic values are concerned - it may never become so small as to render the answer completely unimportant. The latter may be understood as a consequence of our world responsibility.

With these restrictions, moral judgments of foreign cultures and past epochs according to one's own set of values represent the upper limit up to which a rigorous moral absolutism (i.e. the unanimous application or imposition of one's own values in any context) is sensible. However, it is only so, when we judge abstractly about moral systems or about institutions. When we judge the actions of concrete people, this is still too much, because we have to take into account the unavoidable limitations of human nature and especially the fact that anybody's perspective is necessarily limited by the time and culture, he or she is born into and lives in. This will be the topic of the following section.

\subsection{Judgments of People and their Actions}

People in different countries and in different historical epochs act in accordance with the most diverse systems of norms and values. But it is hardly 
possible to accept all these different sets of values on an equal footing, unless we do not wish to take any of them seriously any more. This, however, raises the question of fairness when we form moral judgments about what people did in former times or what people do in other places of the world.

The answer proposed here is that we should judge the actions of concrete people against the background of the moral common sense of their respective culture or historical period. ${ }^{2}$ This simple answer may, at first sight, appear like plain moral relativism, but it is not. "Moral common sense" can be described as the morals that are common knowledge and are in effect over a longer period of time. ${ }^{3}$ Moral common sense as a criterion frees us from the necessity to take account of such sets of moral rules that are only transitory or that remain partial even within one society or that are in the long run not compatible with the necessities of every day's life. This is especially the case for morals that may be characterized as the outcome of fanaticism. Fanaticism is an exceptional state of mind that can hardly be kept up over a longer period of time, and it is to its full extend often only adopted by a subgroup of the society. It may, for a certain while, act as a kind of "Übermoral" that overshadows the common sense moral, but it will never fully replace the common sense moral, although it must be assumed that it can influence the subsequent development of the moral common sense to a certain degree. An example for this kind of "Übermoral" are the morals embodied in the ideologies of totalitarian states. Typically, the totalitarian morals are so excessive that before they have pervaded the whole society they are either broken down or have, before long, been watered down to a much more common sense like version of themselves. That the Nazis made some attempts to hide the annihilation of the Jews from the rest of the population bears proof of the fact that they were aware of the existence of another set of morals according to which genocide is a crime. If they chose to adhere to Nazi morals instead, they can - even under the variant of moral relativism advocated here - be held fully responsible for this choice.

The line of reasoning in the previous paragraph does of course rest on the optimistic empirical assumption that "fanatical morals" are normally not long term stable. But if this is true then we can safely rule out fanatical

\footnotetext{
${ }^{2}$ This idea as well as the following discussion of "Übermoral" is strongly inspired by Hermann Lübbe's treatment of "political moralization" (Lübbe).

${ }^{3}$ This definition is, of course, not very strict, but only intended as a rough explanation to supplement the verbal intuition the phrase "moral common sense" suggests.
} 
morals without risking to be "unfair" to the people acting according to a fanatical set of morals. For, neither do we demand that they act according to an enlightened set of morals that they cannot realistically be expected to take account of (or even just be aware of), nor are we, by taking recourse to the (context dependent) moral common sense, forced to accept the most unreasonable moral excesses.

But is the criterion of moral common sense really sufficient? Several problems this criterion raises suggest that it is too liberal and therefore must be restricted some more:

1. The criterion is ambiguous: There may be situations where several common sense morals are in conflict with each other. Also, the common sense moral is continuously changing. According to which common sense moral shall we then form our judgments?

2. The criterion is conservative: If we slavishly stick to the criteria of moral common sense then we would always have to give bad marks to those people that are ahead of their time. Moral progress would be practically forbidden.

3. The criterion is insufficient in cases, where the traditional morals allow or even demand grave moral vices: While fanaticism may be only short lived, atavisms and superstitions can form an unquestioned part of a moral tradition. An extreme example is that of genital mutilation of girls practiced in some regions of Africa (Amnesty International Report). The practice is so abhorrent that any abstract principle of moral judgment that does not allow to banish it, must be considered insufficient.

1) The first objection does not necessarily call for a restriction of the criterion of moral common sense, but for a further decision on whether it should be applied liberally or in a stricter way. A liberal application would mean that any of the several conflicting common sense morals should be accepted. That is, if some action is right according to one of these different common sense morals, we are not entitled to criticize the person committing it any more. This may lead to contradictions in the sense that possibly opposing actions must both be accepted as morally legitimate. (Borrowing a metaphor from politics, we could say that as outside observers we ought to follow a policy of non-intervention when different common sense morals are in conflict.)

The other way to resolve the conflict between several competing common sense norms would be simply to pick the one that deems us the best (according to our own values) as reference. One might object that this solution essentially breaks the moral relativism to which we have confined our- 
selves when judging the actions of people. But, after all, we have only introduced a limited relativism to avoid unfair moral judgments. The sort of judgments to be excluded on behalf of their unfairness are primarily those where we would implicitly demand from people to become moral inventors in case their conventional morals should prove unacceptable to our enlightened standards. But if we confine what we may call the justified demand of moral self-reflection to the respectable systems of common sense morals competing within the context under discussion then the unfairness is much smaller and may to this extent be justified by our urge not to give in to a fully fledged moral relativism. Of course, whether we ought to choose a liberal or a strict application of the criterion of moral common sense may depend on the particular circumstances, especially the moral importance of the subject matter in question. ${ }^{4}$

2) The second objection can only be met by extending our criterion of moral common sense so that it also includes progressive morals (from our own point of view). Unfortunately, we can now hardly argue for a strict application of the criterion in the above (1) sense any more, because it would seem unfair to expect from the majority of people the appreciation of the progressive point of view right away. What we have gained is only that we are not forced to condemn the progressivists as a consequence of our own criterion. This may in effect lead to "tragic situations", situations where conflicting values clash without even a theoretical possibility of resolution. ${ }^{5}$ 3 ) The third objection could appear to be the most crucial one, because it seems to force us to dilute our criterion of moral common sense by other criteria, like the criterion of moral importance, which otherwise should due to its relatively strong subjectivity - only be applied as a lower rank criterion. But if we think about it a little longer then we might also come to

\footnotetext{
${ }^{4}$ It should be emphasized that even if we chose the liberal application of the criteria of moral common sense, we still need not include fanaticism in the previously described sense, because fanaticism does not even count as common sense moral.

${ }^{5}$ Usually, there are good reasons for avoiding "tragic situations" in any system of ethics: Tragic situations are often just a bad excuse for not taking a stance or for already having chosen the wrong side in the past. More importantly, tragic situations are essentially a type of ethical contradiction and contradictions should by and large be avoided. What appears to be a contradiction in an ethical system is practically a matter that is decided by the right of the strongest. Normally, we do not want that. But if there is really no sensible way to resolve an ethical conflict it might in certain exceptional cases even be the most humane choice to accept tragic situations and thereby the decision according to the right of the strongest. For, then the inferior is still spared from additional moral humiliation of having been illegitimately wrong.
} 
the conclusion that it is especially the case of superstitions and atavisms where the two-tier approach to moral judgments of institutions and norm systems as such and the people acting within these systems pays off. The best way to overcome superstitious customs is by education and tenacious convincing. A moralizing attitude is in danger of producing the adverse effect. The two-tier approach allows us to condemn the practice itself without reacting with moral reproach against the very people that need to be convinced.

If we keep in mind that, following our two-tier approach, the social institutions as such should still be judged rigorously, then the relatively weak criterion of moral common sense may, with the qualifications made above, be morally satisfactory for the judgment of concrete people and their actions.

\section{Objections and Refinement}

The two-tier approach to moral judgments concerning foreign cultures and bygone epochs permits a multifaceted and - as I hope - a much more balanced view than a single set of criteria would. Still, it is open to many objections, the most obvious of which is that it introduces too many and too grave contradictions into our moral reasoning. For example, we can be forced to condemn a certain action taking place in different cultural context because it contradicts one or more of our core values, and at the same time we cannot criticize the person performing this action because he or she acts according to accepted moral standards of his or her culture. I believe that tolerating this kind of contradictions is a lesser evil than either laissez-faire moral relativism or the intercultural arrogance of moral absolutism. (Of course, a certain dose of both relativism as well as Western arrogance is still present in my approach.)

When forming an opinion we can be content with a multifaceted view and, most probably, this is even better than a single sided view. But when we have to take decisions these should be taken unanimously. The problem becomes urgent, for example, when we have to decide on how to deal with immigrant subcultures that bring their own traditional values, some of which might come into conflict with moral standards of the host society. There can be only one law in one country, so that at least when the conflict comes down to legal matters, we will probably have to revert to a solution that is more in the spirit of moral absolutism. Still, our judgments will be more reasoned if we keep in mind that the problem as such is not as simple. 
Quite the opposite becomes true, when we are concerned with intercultural dialogue. One can hardly start profitable a dialogue on the basis of a claim of moral superiority. A dialogue can only succeed when the partners talk to each other on an equal footing, which requires an attitude that may be termed the willing relativism of dialogue. This does not mean that we are not allowed to stand by our moral convictions, but prima facie we will look at the convictions of the others as equally respectable.

Summing it up, the two-tier approach to moral judgments expounded here will in many concrete situations have to be resolved to a more univocal point of view or judgment. However, putting the step of resolving at the end (in situations where this is necessary) has the heuristic advantage to allow more well reasoned judgments over the alternative of deciding definitely on a system of values first. It allows us to criticize moral standards that we strongly reject without having to react in an irritated way against the people who comply with them. The moral judgments arrived at by the two-tier approach will therefore probably be more satisfactory than otherwise.

\section{REFERENCES}

Amnesty International Report. female genital mutilation. internet, 2004. URL: http://www.amnesty.org/ailib/intcam/femgen/fgm1.htm.

Diamond, J. 2005 Collapse. How Societies Choose to Fail or Survive, Toronto: Viking. Fox, R.L. 2005 Alexander der Große. Eroberer der Welt, Stuttgart: Klett-Cotta, $4^{\text {th }}$ edition.

Lübbe, H. 1987 Politischer Moralismus. Der Triumph der Gesinnung über die Urteilskraft, Berlin: Siedler.

Schmidt, M.G. 2000 Demokratietheorien, Opladen: Leske+Budrich, $3^{\text {rd }}$ edition.

Weber, M. 1906 Kritische Studien auf dem Gebiet der kulturwissenschaftlichen Logik, II. Objektive Möglichkeit und adäquate Verursachung in der historischen Kausalbetrachtung, chapter III, pages 266-290. Tübingen: J.C.B. Mohr, $7^{\text {th }}$ edition. 